\title{
(2) OPEN ACCESS \\ Argon laser photocoagulation for treatment of presumed trematode-induced granulomatous anterior uveitis in children
}

\author{
Alahmady Hamad Alsmman 주, ${ }^{1}$ Abdelsalam Abdalla, ${ }^{2}$ Mohammed Ezzeldawla, \\ Elshimaa A Mateen Mossa (i) , ${ }^{1}$ Mortada Abozaid (1) ${ }^{1}$
}

\begin{abstract}
- Additional supplemental material is published online only. To view, please visit the journal online (http://dx.doi. org/10.1136/bjophthalmol2021-318796)
\end{abstract}

Department of Ophthalmology, Faculty of Medicine, Sohag University, Sohag, Egypt ${ }^{2}$ Department of Ophthalmology, Faculty of Medicine, Assiut University, Assiut, Egypt

\section{Correspondence to}

Dr Mortada Abozaid, Department of Ophthalmology, Faculty of Medicine, Sohag University, Sohag, Egypt; mourtada_abdelaal@med. sohag.edu.eg

Received 6 January 2021 Accepted 1 June 2021

\section{Check for updates}

(C) Author(s) (or their employer(s)) 2021. Re-use permitted under CC BY-NC. No commercial re-use. See rights and permissions. Published by BMJ.

To cite: Alsmman $\mathrm{AH}$, Abdalla A, Ezzeldawla M et al. Br J Ophthalmol Epub ahead of print: [please include Day Month Year]. doi:10.1136/

bjophthalmol-2021-318796

\begin{abstract}
Background/Aims To assess the safety and efficacy of argon laser photocoagulation as a new modality for the treatment of presumed trematode-induced granulomatous anterior uveitis (PTGAU) in children. Methods Forty-eight eyes of 48 children with PTGAU with pearl-like nodule(s) in the anterior chamber were included in this prospective non-randomised controlled clinical trial. The patients were divided into two groups: those in Group A (23 eyes) were treated with one session of argon laser applied to the anterior chamber nodules and those in Group B (25 eyes) received medical treatment in the form of topical steroid and cycloplegic eye drops with trans-septal triamcinolone injections. All cases were followed up for 3 months with measurement of visual acuity (VA), assessment of the anterior chamber reaction and measurement of the pearl-like nodule size.

Results In Group A, 22 eyes (95.65\%) showed regression of the pearl-like nodules with resolution of the anterior chamber reaction (flare and cells) and improvement in visual acuity from $0.52 \pm 0.12$ to $0.06 \pm 0.08 \log \operatorname{MAR}(p<0.001)$. Such improvement was maintained within the 3-month follow-up period. In Group B, 23 eyes (92\%) showed initial regression of the granulomas, which was maintained in only 14 eyes $(56 \%)$, with nine eyes experiencing recurrence after 3 months of follow-up.

Conclusion Argon laser photocoagulation is a safe and effective novel treatment for PTGAU with pearllike nodules in the anterior chamber in children. Larger studies with longer follow-up periods are needed to confirm these results.
\end{abstract}

\section{INTRODUCTION}

Presumed trematode-induced granulomatous anterior uveitis (PTGAU) is a relatively common anterior uveitis among paediatric patients from rural Egypt. It has been linked to swimming or bathing in the Nile river and freshwater canals. ${ }^{12}$ It is characterised by chronic granulomatous iridocyclitis with one or more pearl-like nodules (pearl tumour) of variable sizes and locations within the anterior chamber (AC) with or without subconjunctival nodules. Some cases might be associated with intermediate or posterior uveitis. Most cases occur in boys who present with acute exacerbations of iridocyclitis, resulting in complications that threaten vision, such as synechiae, cataract, glaucoma and/ or phthisis bulbi. In addition, untreated granulomas usually heal by fibrosis, leaving a permanent scar, which can be visually significant. ${ }^{3-6}$ Molecular evidence of digenic trematode as a cause of this distinct form of uveitis was reported in a recent study. ${ }^{7}$

Schistosomiasis or bilharziasis is an endemic disease in Egypt. It is caused by the Schistosoma genus (flat trematodes or blood flukes), which can induce granulomatous reactions in ocular tissues around the eggs or adult worms. ${ }^{8-10}$ Schistosoma mansoni was isolated from the AC in several cases of ocular schistosomiasis. ${ }^{11}$

The treatment options for this granulomatous uveitis include topical steroid and cycloplegic, trans-septal steroid and systemic steroid and antiparasitic administration, limbal cryotherapy ${ }^{12}$ and surgical excision. ${ }^{1}$ However, many children may develop complications from conservative treatments, especially after steroid administration or surgical intervention. ${ }^{13}$

Since its invention in 1964 by William Bridges, the argon laser has been used in numerous ophthalmic conditions because of its precision in targeting the intended structures, especially in glaucoma and retinal photocoagulation procedures. In addition, it is used in many dermatological lesions such as ulcers and polyps. ${ }^{14}$

In this non-randomised controlled clinical trial, we assessed a new modality of treatment in the form of argon laser photocoagulation of the pearllike nodules in the AC and compared the obtained results to those of the control group which included patients that received medical treatment. In the absence of animal models, we relied on a pilot set of data formed from three cases to confirm the safety and efficacy of the procedure before proceeding with the clinical trial.

\section{PATIENTS AND METHODS}

This study was conducted between May and October 2020 at the Ophthalmology Department of Sohag University Hospital in collaboration with the Nour-Eloyoun private centre in Sohag, Egypt. The study was also registered as a clinical trial in the Pan African Clinical Trial Registry (registry number: PACTR202008516974176). After explanation of the procedure's benefits and risks, written informed consent was obtained from the parents of the participants.

Forty-eight children (aged $<18$ years) with active PTGAU were included in the study. The inclusion criteria were as follows: one or two pearl-like 
masses in the AC sized $<3 \mathrm{~mm}$, flare and cells $\geq+1$ according to the Standardised Uveitis Nomenclature (SUN) classification, and a visual acuity $>6 / 60$ in the affected eye.

The exclusion criteria were as follows: presence of inactive scarred membranous lesions; previous diagnosis of cataract, glaucoma or phthisis bulbi; and ocular trauma or surgery history. Patients with a known cause of uveitis or systemic granulomatous disease were also excluded.

All patients underwent a complete ophthalmological evaluation including detailed records regarding the onset and course of the iritis and its relation to river water exposure. Ocular examination was performed via slit lamp evaluation and included documentation of the number and size of pearl-like lesions as well as grading the AC reaction of cells and flare according to the SUN nomenclature. ${ }^{15}$ Visual acuity (corrected and uncorrected) and intraocular pressure (IOP) were measured, and a fundus examination was also performed. To confirm diagnosis and exclude other causes of anterior uveitis, a systemic work-up examination was performed in all cases in the form of stool and urine analysis, chest X-ray, complete blood count, erythrocyte sedimentation rate and antibilharzial antibody titre examinations.

The children were divided into two groups according to the consent obtained from their parents; those whose parents agreed to perform surgical intervention in the form of one session of argon laser were included in Group A (23 eyes), while those whose parents refused such treatment were included in Group B (25 eyes).

\section{Surgical technique performed in Group A}

Under topical anaesthesia, all cases received one session of argon laser photocoagulation applied directly to the pearl-like lesions in the AC through the argon laser lens. The settings of the argon laser were as follows: spot size, $100-200 \mu \mathrm{m}$; duration, $0.2-0.4$ $\mathrm{s}$; power, 250-400 mJ; shots, 10-25, depending on the response of the lesion (blanching and shrinkage) (figure 1). All procedures were performed by two surgeons (AHA and MA).

\section{Perioperative treatment}

Topical steroid and cycloplegic administration was initiated at 3 days before the session. The following topical eye drops were used postoperatively: gatifloxacin $0.3 \%$, five times a day for 1 week; prednisolone acetate $1 \%$, five times a day with gradual taper for $>4$ weeks; cyclopentolate hydrochloride three times a day for 3 days; brimonidine, two times a day for 1 week.

\section{Medical treatment in Group B}

Patients whose parents refused surgical intervention were given the following conservative regimen:
1. Trans-septal (orbital floor) triamcinolone acetonide $(40 \mathrm{mg}$ / $\mathrm{mL}$ ) injection under topical anaesthesia after reassurance of the patients.

2. Topical prednisolone acetate $1 \%$ eye drops, five times a day with a gradual taper for $>4$ weeks.

3. Cyclopentolate hydrochloride $1 \%$, three times a day for 2 weeks.

4. Topical gatifloxacin $0.3 \%$ eye drops, five times a day for 1 week (prophylactic use to prevent secondary bacterial conjunctivitis).

\section{Follow-up schedule}

All patients in the two groups were examined after 1 day, 2 weeks, 1 month and 3 months to record their visual acuity, IOP, grade of AC reaction and presence of the AC granulomas. Treatment is considered successful when there is resolution the AC reaction (according to SUN definition) together with disappearance of the AC nodule(s) and improvement of the visual acuity.

\section{Statistical analysis}

Because of the absence of previous similar studies, the sample size calculation was difficult. Instead, we included all cases that fulfilled the inclusion criteria within a certain period of time.

Data were analysed using IBM SPSS Statistics for Windows V.20.0 (IBM, Armonk, New York, USA).

Quantitative data were expressed as median and IQR. Qualitative data were expressed as numbers and percentages. The data were tested for normality using the Shapiro-Wilk test. An independent samples test was used for normally distributed data. The nonparametric Mann-Whitney and Friedman tests were used for data that were not normally distributed.

The $\chi^{2}$ and Fisher's exact tests were used for comparison of qualitative variables as appropriate. The Friedman test was used for comparison between the repeated AC cell measures of the studied patients. Cochran's Q test was used for comparison between repeated granuloma examinations of the studied patients (online supplemental tables 1-8). The level of significance was set at $\mathrm{p}<0.05$.

\section{RESULTS}

This clinical trial included 48 eyes of 48 children with PTGAU and pearl-like nodules in the AC. The patients were divided into two groups: Group A included 23 eyes which were treated by one session of argon laser applied to the AC nodules and Group $\mathrm{B}$ included 25 eyes which received conservative medical treatment. The two groups showed no differences concerning their baseline demographics or ocular findings (best-corrected visual acuity, AC cells and number of AC nodules), as shown in table 1.
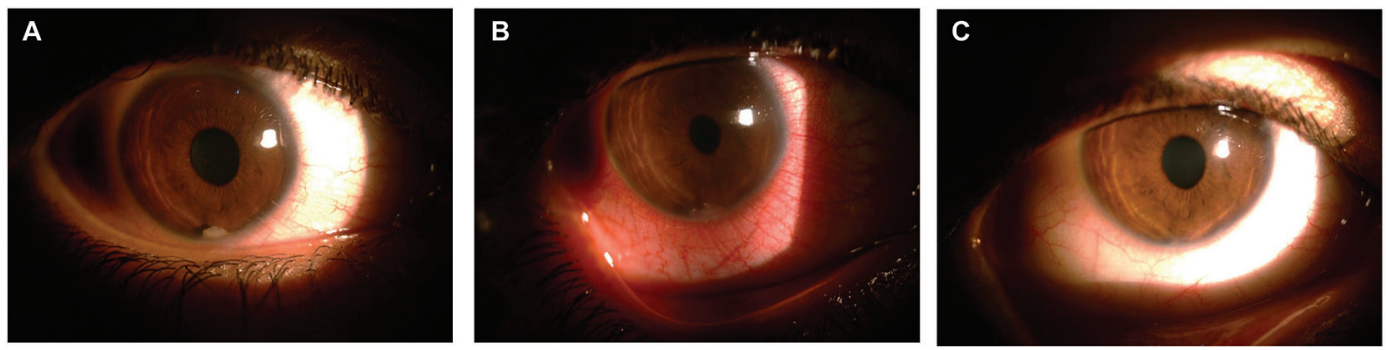

Figure 1 The case of a 14-year-old patient, included in Group A, with single AC granuloma at the 6 o'clock position is presented. The findings (A) before, (B) immediately after and (C) at 3 months after argon laser photocoagulation performance are presented. 
Table 1 comparison between the two study groups regarding their preoperative measures

\begin{tabular}{|c|c|c|c|}
\hline Characteristics & $\begin{array}{l}\text { Group A } \\
(n=23)\end{array}$ & $\begin{array}{l}\text { Group B } \\
(n=25)\end{array}$ & $P$ value \\
\hline \multicolumn{4}{|l|}{ Age (year) } \\
\hline Mean \pm SD & $11.17 \pm 1.72$ & $11.4 \pm 1.89$ & \multirow[t]{2}{*}{$0.668^{*}$} \\
\hline Median (IQR) & $11(10-12)$ & $12(10-13)$ & \\
\hline \multicolumn{4}{|l|}{ Sex } \\
\hline Female & $1(4.35 \%)$ & $1(4 \%)$ & \multirow[t]{2}{*}{$1 \dagger$} \\
\hline Male & $22(95.65 \%)$ & $24(96 \%)$ & \\
\hline \multicolumn{4}{|c|}{ Best-corrected visual acuity (logMAR) } \\
\hline Mean \pm SD & $0.52 \pm 0.12$ & $0.53 \pm 0.12$ & \multirow[t]{2}{*}{$0.924 \ddagger$} \\
\hline Median (IQR) & $0.5(0.4-0.6)$ & $0.5(0.4-0.6)$ & \\
\hline \multicolumn{4}{|c|}{ Anterior chamber cells } \\
\hline 1 & $2(8.7 \%)$ & $2(8 \%)$ & \multirow[t]{3}{*}{$0.812 \S$} \\
\hline 2 & $18(78.26 \%)$ & $18(72 \%)$ & \\
\hline 3 & $3(13.04 \%)$ & $5(20 \%)$ & \\
\hline \multicolumn{4}{|c|}{ Anterior chamber nodules } \\
\hline 1 & $19(82.61 \%)$ & $21(84 \%)$ & \multirow[t]{3}{*}{$0.559 \S$} \\
\hline 2 & $4(17.39 \%)$ & $3(12 \%)$ & \\
\hline 3 & $0(0.0 \%)$ & $1(4 \%)$ & \\
\hline
\end{tabular}

${ }^{*} \mathrm{P}$ value was calculated by Independent Samples Test.

tP value was calculated by Fisher's Exact Test.

$\ddagger P$ value was calculated by Mann-Whitney $U$ test.

$\S P$ value was calculated by Chi-Square test.

The results of the systemic investigations were irrelevant, with antibilharzial antibodies being positive in 12 cases from Group A and 10 cases from Group B. The mean age of patients of Group A was $11.17 \pm 1.72$ (range, $8-14$ ) years, while that of Group B was $11.4 \pm 1.89(8-14)$ years. Most children were boys with a history of swimming or bathing in the Nile river, which can be explained by the cultural aspects that prevent girls from bathing or swimming in the water of the Nile river or its canals.

The preoperative mean best-corrected visual acuity (BCVA) value in Group A was $0.52 \pm 0.12(\log M A R)$, while the postoperative mean BCVA values were $0.22 \pm 0.1,0.11 \pm 0.08$ and $0.06 \pm 0.08$ after 2 weeks, 1 month and 3 months, respectively $(\mathrm{p}<0.001)$. The number of cases with +2 and +3 AC cells decreased from 21 preoperatively to 0 at the 3 -month follow-up

Table 2 Comparison between the repeated examinations of AC cells in the two groups

\begin{tabular}{|c|c|c|c|c|c|}
\hline \multirow[b]{2}{*}{ Grade } & \multicolumn{4}{|c|}{ Anterior chamber cells } & \multirow[b]{2}{*}{$P$ value } \\
\hline & Preoperative & $\begin{array}{l}\text { Two weeks } \\
\text { postoperative }\end{array}$ & $\begin{array}{l}\text { One month } \\
\text { postoperative }\end{array}$ & $\begin{array}{l}\text { Three months } \\
\text { postoperative }\end{array}$ & \\
\hline \multicolumn{6}{|c|}{ Group A } \\
\hline 0 & $0(0.0 \%)$ & $3(13.04 \%)$ & 20 (86.96\%) & $19(82.6 \%)$ & \multirow[t]{5}{*}{$<0.001$ * } \\
\hline 0.5 & $0(0.0 \%)$ & 11 (47.83\%) & $3(13.04 \%)$ & $2(8.7 \%)$ & \\
\hline 1 & $2(8.7 \%)$ & $9(39.13 \%)$ & $0(0.0 \%)$ & $2(8.7 \%)$ & \\
\hline 2 & $18(78.26 \%)$ & $0(0.0 \%)$ & $0(0.0 \%)$ & $0(0.0 \%)$ & \\
\hline 3 & $3(13.04 \%)$ & $0(0.0 \%)$ & $0(0.0 \%)$ & $0(0.0 \%)$ & \\
\hline \multicolumn{6}{|c|}{ Group B } \\
\hline 0 & $0(0.0 \%)$ & $3(12 \%)$ & $19(76 \%)$ & $13(52 \%)$ & \multirow[t]{5}{*}{$<0.001^{*}$} \\
\hline 0.5 & $0(0.0 \%)$ & $7(28 \%)$ & $5(20 \%)$ & $5(20 \%)$ & \\
\hline 1 & $2(8 \%)$ & $14(56 \%)$ & $1(4 \%)$ & $7(28 \%)$ & \\
\hline 2 & $18(72 \%)$ & $1(4 \%)$ & $0(0.0 \%)$ & $0(0.0 \%)$ & \\
\hline 3 & $5(20 \%)$ & $0(0.0 \%)$ & $0(0.0 \%)$ & $0(0.0 \%)$ & \\
\hline
\end{tabular}

${ }^{*} \mathrm{P}$ value was calculated by Friedman test.
Table 3 Comparison between the repeated granuloma examinations in the two groups

\begin{tabular}{cllll}
\hline & \multicolumn{2}{l}{ Granuloma } & & \\
\cline { 2 - 3 } Characteristics & $\begin{array}{l}\text { Two weeks } \\
\text { postoperative }\end{array}$ & $\begin{array}{l}\text { One-month } \\
\text { postoperative }\end{array}$ & $\begin{array}{l}\text { Three months } \\
\text { postoperative }\end{array}$ & P value \\
\hline Group A & & & & \\
Resolved & $17(73.91 \%)$ & $22(95.65 \%)$ & $22(95.65 \%)$ & $0.007^{*}$ \\
Unresolved & $6(26.09 \%)$ & $1(4.35 \%)$ & $1(4.35 \%)$ & \\
Group B & & & & $0.001^{*}$ \\
Resolved & $17(68 \%)$ & $23(92 \%)$ & $14(56 \%)$ & \\
Unresolved & $8(32 \%)$ & $2(8 \%)$ & $11(44 \%)$ & \\
\hline
\end{tabular}

${ }^{*} \mathrm{P}$ value was calculated by Cochran's $\mathrm{Q}$ test.

examination (table 2). The AC nodule(s) disappeared (resolved) in 22 cases (95.65\%), with resolution of the AC reaction within 2-4 weeks. This response was maintained throughout the 3-month follow-up period (table 3).

No serious complications were detected during or after performing the argon laser session. Only one case showed an increase in IOP $(27 \mathrm{~mm} \mathrm{Hg})$ the day after the argon laser session, which was successfully managed with a topical beta-blocker in addition to brimonidine. In addition, hyphaema was noticed in one case immediately after the session (figure 2) and resolved completely within 5 days. Only one case in Group A showed resistance to photocoagulation with minimal initial shrinkage (reduced in size from 2 to $1 \mathrm{~mm}$ ) followed by recurrence within 3 months. This patient now receives medical treatment until the arrangement of a second argon laser session.

In Group B, the preoperative mean BCVA value was $0.53 \pm 12$ $(\log \mathrm{MAR})$, while the postoperative mean BCVA values were $0.24 \pm 0.01,0.1 \pm 0.07$ and $0.16 \pm 0.17$ after 2 weeks, 1 month and 3 months, respectively $(\mathrm{p}<0.001)$. The number of cases with +2 and +3 AC cells decreased from 23 preoperatively to 0 after 3 months of follow-up; however, the cases with +0.5 and +1 increased from 2 to 12 in the same time period (table 2). The AC nodule(s) disappeared (resolved) in 23 cases (92\%) within 1 month after the initiation of medical treatment with resolution of uveitis. However, 9 of these 23 cases showed recurrence by the end of the 3-month follow-up period, with reappearance of the AC reaction. The percentage of nodules that had disappeared decreased to $56 \%$ (table 3, figure 3).

No complications were reported after providing the transseptal triamcinolone injection, and no cases of cataract or steroid induced glaucoma were detected.
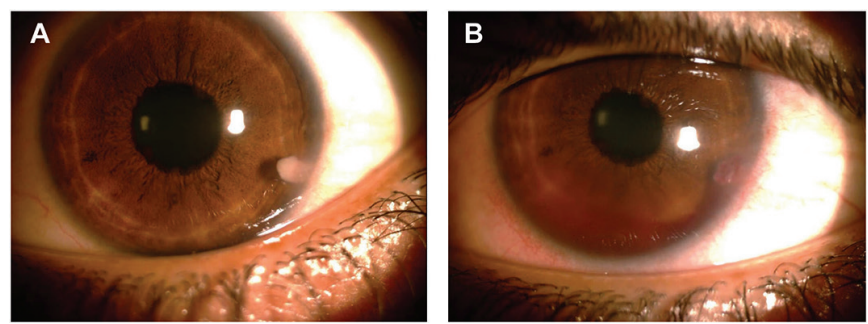

Figure 2 The case of a 12-year-old patient included in Group A with single AC granuloma at the 3 o'clock position that was complicated by postoperative hyphaema is presented. The findings $(A)$ before and (B) immediately after argon laser photocoagulation performance are presented. 


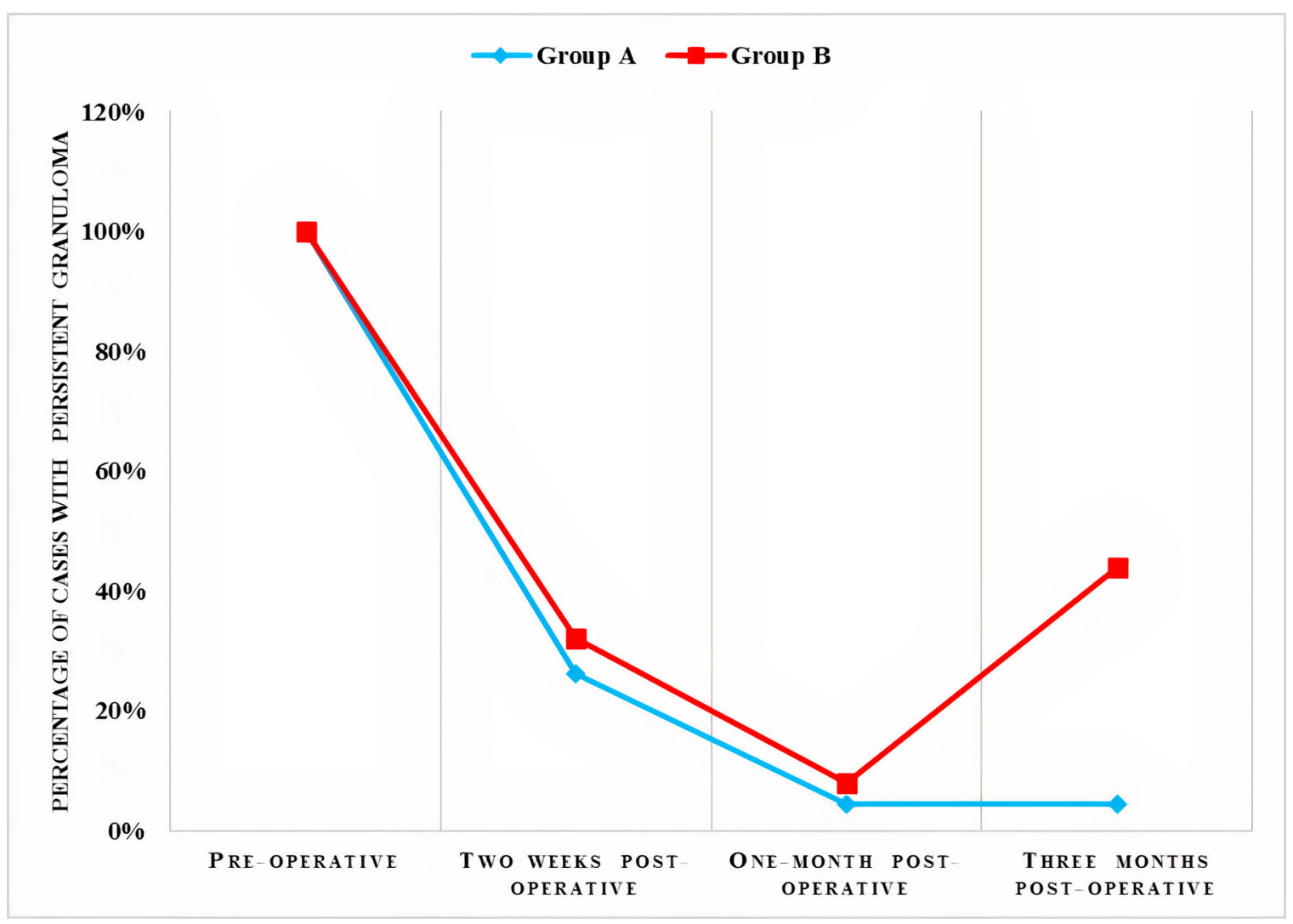

Figure 3 A rise in the percentage of persistent granulomas after initial decline in Group B compared with a maintained decline demonstrated in Group A.

\section{DISCUSSION}

Schistosomiasis or bilharziasis has been endemic in Egypt for thousands of years and is associated with many life-threatening complications, such as hepatic failure and cancer of the urinary bladder. Because of the antiparasitic praziquantel and mass education regarding the seriousness and transmission of the disease, bilharziasis has been brought under control over the last few decades. However, Upper Egypt (the southern part of Egypt) still suffers from a relatively high infestation rate, mostly because of its agricultural environment and the low socioeconomic status of the inhabitants especially in Sohag governorate where this study was performed. ${ }^{16}$

PTGAU is a potentially blinding ocular condition associated with bathing or swimming in local river water, such as that of the Nile river in Egypt. Although bilharzial trematode has not yet been isolated from the AC granuloma, Schistosoma haematobium, being the most prevalent trematode in Upper Egypt, could be the likely cause of this condition in Sohag governorate.

Many children with this disease do not respond well to topical or systemic medical treatment and thus require more aggressive forms of treatment, such as surgical excision, with potential complications including those of general anaesthesia.

In this pilot study, we reported the safety and efficacy of argon laser photocoagulation of the pearl-like nodules in the AC of patients with PTGAU. Forty-eight eyes of 48 children with PTGAU associated with one or two pearl-like nodules in the AC were included in this clinical trial. The cases were divided into two groups: those in the first group or Group A were treated with one session of argon laser photocoagulation applied to the pearllike nodule(s) with perioperative topical steroid and cycloplegic administration. Those in the second group or Group B were treated conservatively with trans-septal steroid, topical steroid, and cycloplegic administration. After 3 months of observation, a statistically significant difference in the outcome was detected between the two groups, with marked improvement in the argon laser group as revealed by the better visual acuity, better control of inflammation and lower rate of recurrence observed after the treatment completion $(\mathrm{p}=0.002)$.

The mechanism of action of argon laser in these nonpigmented nodules is obscure. When the argon laser is applied to a lesion containing melanin pigment or oxyhaemoglobin of its blood vessels, it is absorbed and converted into thermal energy which causes coagulation and necrosis of the lesion. In many cases of diffuse unilateral subacute neuroretinitis, argon laser photocoagulation was successfully used to destroy the motile white nematode when seen in the subretinal space. ${ }^{17}$ Accordingly, a possible mechanism of action of the argon laser in this study was the destruction or thermal ablation of the pearl-like nodules in the AC, which might be associated with parts of the trematode larvae or adult worm, thus eliminating the antigenic stimulant of the relapsing granulomatous anterior uveitis.

The main limitation of this study was the inclusion of mild or moderate cases only of PTGAU by excluding cases with large AC nodules $(>3 \mathrm{~mm})$ or marked drop of visual acuity $(<6 / 60)$. We excluded such cases to ensure a reasonable degree of homogeneity between the two groups and to avoid complications that may occur in more severe cases while trying a new modality of treatment. Such severe cases of the disease can be included in future studies.

Although the milder form of the disease could be treated medically with great success, the recurrence rate has remained higher in the control group than in the argon laser group.

In their prospective case series, El Nokrashy et al ${ }^{18}$ assessed the efficacy of both systemic antiparasitic treatment alone and that 
of the systemic antiparasitic treatment combined with surgical aspiration in 30 eyes of 30 children with PTGAU presenting with AC granuloma. They concluded that antiparasitic treatment alone (praziquantel+metronidazole) was effective for small granulomas, while the provided surgical aspiration was a satisfactory adjuvant treatment for large granulomas.

Amin $e t a l^{19}$ reported the clinical prescription and laboratory analysis results of 110 Egyptian children with PTGAU. Surgical excision of the lesions was performed in 14 cases. Histopathological examination of these lesions after removal revealed granulomatous inflammation formed by central suppuration surrounded by epithelioid cells and sheets of lymphocytes. PCR analysis performed for 6 out of 14 samples showed positive results for trematode DNA.

Sadek et al compared the outcomes of medical treatment to surgical intervention (excision of granuloma and AC wash) in 41 eyes of 39 patients with active infection, defined as flare and cells $\geq+2$ and the presence of a white AC granuloma $>3 \mathrm{~mm} .{ }^{20}$

After 2 weeks, the granuloma disappeared in 20 out of 21 eyes in the surgical group, while it disappeared in only 2 out of 20 eyes in the conservative treatment group. They concluded that surgical excision of large granulomas may result in a more rapid and complete cure. To the best of our knowledge, this study was the first to test the use of argon laser photocoagulation for the treatment of patients with PTGAU. The technique is simple, cheap, non-invasive, and widely available in the developing countries. While the results are encouraging, future studies with larger samples and longer follow-up durations are needed to confirm our findings.

Acknowledgements We would like to thank Editage (www.editage.com) for English language editing.

Contributors AHA and MA initiated the study design and performed the surgical treatment. AA, ME and EAMM helped with the implementation of the study, collection of data and analysis of the results. All authors shared in writing and approving the final manuscript.

Funding None.

Competing interests None declared.

Patient consent for publication Not required.

Ethics approval The study followed the tenets of the Declaration of Helsinki and was approved by the ethical committee of the Sohag Faculty of Medicine (approval number: IBR \# S20-131).

Provenance and peer review Not commissioned; externally peer reviewed.

Data availability statement Data are available on reasonable request. All data relevant to the study are included in the article or uploaded as supplementary information.

Supplemental material This content has been supplied by the author(s). It has not been vetted by BMJ Publishing Group Limited (BMJ) and may not have been peer-reviewed. Any opinions or recommendations discussed are solely those of the author(s) and are not endorsed by BMJ. BMJ disclaims all liability and responsibility arising from any reliance placed on the content. Where the content includes any translated material, BMJ does not warrant the accuracy and reliability of the translations (including but not limited to local regulations, clinical guidelines, terminology, drug names and drug dosages), and is not responsible for any error and/or omissions arising from translation and adaptation or otherwise.

Open access This is an open access article distributed in accordance with the Creative Commons Attribution Non Commercial (CC BY-NC 4.0) license, which permits others to distribute, remix, adapt, build upon this work non-commercially, and license their derivative works on different terms, provided the original work is properly cited, appropriate credit is given, any changes made indicated, and the use is non-commercial. See: http://creativecommons.org/licenses/by-nc/4.0/.

\section{ORCID iDs}

Alahmady Hamad Alsmman http://orcid.org/0000-0001-6436-5576

Elshimaa A Mateen Mossa http://orcid.org/0000-0001-6989-7483

Mortada Abozaid http://orcid.org/0000-0002-0161-8035

\section{REFERENCES}

1 Amin RM, Radwan AE, Goweida MB, et al. Management of presumed trematode induced granulomatous uveitis in pediatric patients. Jpn J Ophthalmol 2019;63:119-25.

2 Amin RM, Goweida M, Bedda A, et al. Clinical patterns and causes of intraocular inflammation in a uveitis patient cohort from Egypt. Ocul Immunol Inflamm 2019;27:859-67.

3 Rathinam SR, Usha KR, Rao NA. Presumed trematode-induced granulomatous anterior uveitis: a newly recognized cause of intraocular inflammation in children from South India. Am J Ophthalmol 2002;133:773-9.

4 Rathinam S, Fritsche TR, Srinivasan M, et al. An outbreak of trematode-induced granulomas of the conjunctiva. Ophthalmology 2001;108:1223-9.

5 Arya LK, Rathinam SR, Lalitha P, et al. Trematode fluke Procerovum varium as cause of ocular inflammation in children, South India. Emerg Infect Dis 2016;22:192-200.

6 Rahimi M, Oustad M, Ashrafi A. Demographic and clinical features of pediatric uveitis at a tertiary referral center in Iran. Middle East Afr J Ophthalmol 2016;23:237-40.

7 Rathinam SR, Arya LK, Usha KR, et al. Novel etiological agent: molecular evidence for trematode-induced anterior uveitis in children. Arch Ophthalmol 2012;130:1481-4.

8 Abboud IA, Hanna LS, Ragab HA. Experimental ocular schistosomiasis. Br J Ophthalmol 1971:55:106-15.

9 Nimir AR, Saliem A, Ibrahim IAA. Ophthalmic parasitosis: a review article. Interdiscip Perspect Infect Dis 2012;2012:1-12.

10 Gryseels B. Schistosomiasis. Infect Dis Clin North Am 2012;26:383-97.

11 Newton JC, Kanchanaranya C, Previte LR. Intraocular Schistosoma mansoni. Am J Ophthalmol 1968;65:774-8.

12 Venugopal N, Kummararaj G, Kummararaj S. Cryotherapy for presumed parasitic angle granuloma causing acute anterior granulomatous uveitis. Indian J Ophthalmol 2013;61:135-6.

13 Butcher JM, Austin M, McGalliard J, et al. Bilateral cataracts and glaucoma induced by long term use of steroid eye drops. BMJ 1994;309:43

14 L'Esperance FA. Clinical applications of the organic dye laser. Ophthalmology 1985;92:1592-600

15 Jabs DA, Nussenblatt RB, Rosenbaum JT, et al. Standardization of uveitis Nomenclature for reporting clinical data. Results of the first International workshop. Am J Ophthalmol 2005;140:509-16.

16 Barakat RMR. Epidemiology of schistosomiasis in Egypt: travel through time: review. J Adv Res 2013;4:425-32.

17 Myint K, Sahay R, Mon S, et al. "Worm in the eye": the rationale for treatment of DUSN in south India. Br J Ophthalmol 2006;90:1125-7.

18 El Nokrashy A, Abou Samra W, Sobeih D, et al. Treatment of presumed trematodeinduced granulomatous anterior uveitis among children in rural areas of Egypt. Eye 2019;33:1525-33.

19 Amin RM, Goweida MB, El Goweini HF, et al. Trematodal granulomatous uveitis in paediatric Egyptian patients: a case series. Br J Ophthalmol 2017;101:999-1002.

20 Sadek SH, Ahmed MN, Kamal MA, et al. Anterior chamber granuloma: conservative treatment versus surgical intervention. Acta Ophthalmol 2020;98:1111. 